\title{
Green nanoparticle fabrication and green inhibitors to conserve environment, energy and economy
}

\author{
Alka Sharma \\ Centre of Advanced Study, Department of Chemistry, University of Rajasthan-302 004, Jaipur, India \\ Email: sharma_alka21@yahoo.com
}

An enormous sector of our country's economy is based on industry with natural resources as the backbone which can be further reinforced by their pertinent utilization. Metals are precious resources which need to be dealt with utmost care in terms of recycle, reuse, conservation and protection. Under the strict environmental legislations surveillance, it's utmost to develop significantly efficient corrosion inhibitors via greener routes [1-3]. The indigenous natural resources which are toxic, harmful and waste were investigated to generate novel green inhibitors as well as metal-nano particles (GNPs). Most of these noxious plants are richly constituted with polyphenols, vitamins, gallic acid, tannic acid, quinones, alkaloids etc. To endorse the inhibitive and protective propensity of these weeds, various surface morphological and adsorptive analyses, viz., SEM (Figure 1), AFM (Figure 2), FT-IR spectroscopy, QCA (Figure 3), UV-Visible spectroscopy etc. were carried out. Metal dissolution was slowed downed drastically (almost $\sim 90 \%$ ), these green inhibitor can be very effectively used in metal coating, paints etc. so as to eradicate the usages of toxic chemicals. Furthermore, the noxious weeds generate considerable quality of nanoparticles (GNPs) and they too can be very efficiently used as corrosion impeders.

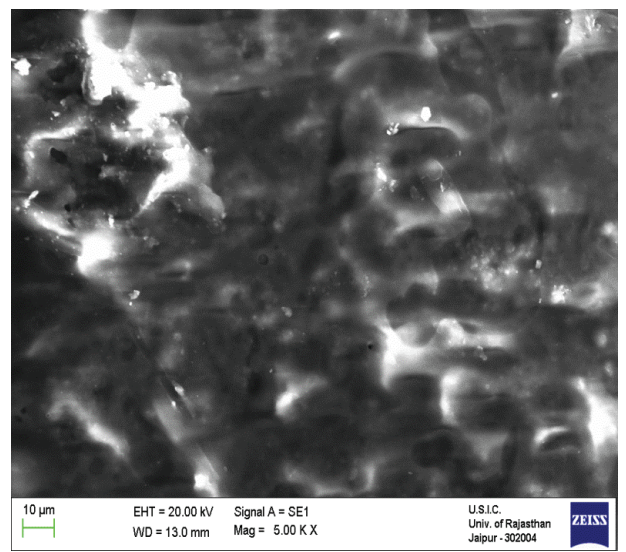

Figure 1: SEM image of inhibited coupon
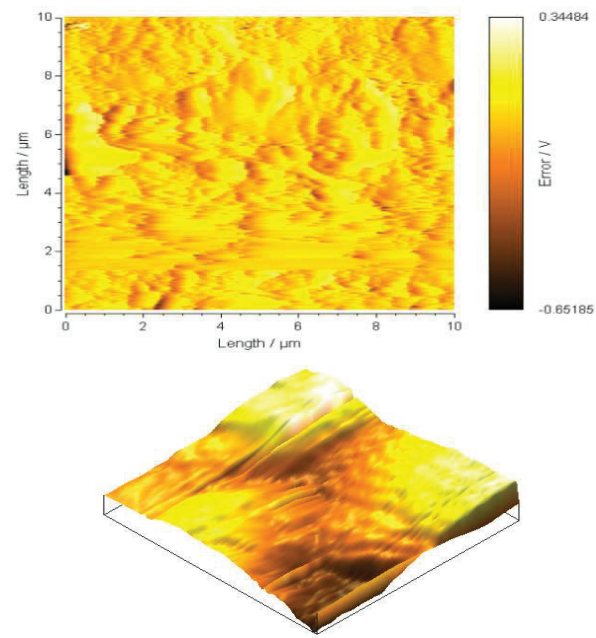

Figure 2: AFM images of inhibited coupon

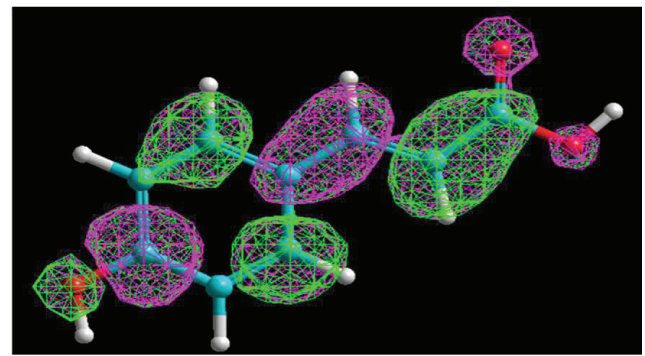

Figure 3: QCA: 3-D surfaces of total charge density of active constituent ( $\mathrm{p}$-Coumaric acid) of a Noxious weed

Keywords: green inhibitors, adsorptive parameters, UV-Visible, SEM, QCA, AFM

\section{References}

1. Alka Sharma, Green Corrosion Inhibitors: Status in Developing Countries. in: Green Corrosion Chemistry and Engineering: Opportunities and Challenges; Germany: Wiley-VCH Verlag GmbH \& Co. KGaA, (2012) 157-180.

2. R. Zandi Zand, Victoria Flexer, $M$ De Keersmaecker, Kim Verbeken, Annemie Adriaens, Int. J. Electrochem. Sci., 10 (2015) 997-1014.

3. Shakeel Ahmed, Mudasir Ahmad, Babu Lal Swami, Saiqa Ikram, J. Adv. Res., 7 (1) (2016) 1728. 